\title{
The Adenosine Antagonist Theophylline Impairs P50 Auditory Sensory Gating in Normal Subjects
}

\author{
Eduardo S. Ghisolfi, M.D., Alexandre S. Prokopiuk, Jefferson Becker, M.D., João A. Ehlers, M.D., \\ Paulo Belmonte-de-Abreu, M.D., Ph.D., Diogo O. Souza, M.D., Ph.D., \\ and Diogo R. Lara, M.D., Ph.D.
}

In the P50 suppression paradigm, when two auditory stimuli are presented $500 \mathrm{~ms}$ apart, the amplitude of the second response (S2), compared with the first (S1), is markedly attenuated in healthy subjects. This is an index of sensory gating. Most schizophrenic patients fail to inhibit the P50 response to the second stimulus, which is assumed to reflect an inhibitory deficit. Adenosine is a neuromodulator with mostly inhibitory activity which is released by physiological stimuli. Since this inhibitory pattern resembles the phenomenon of sensory gating, the contribution of adenosine to P50 suppression was investigated in normal volunteers after treatment with the adenosine antagonist theophylline or placebo. P50 recordings were conducted in thirteen healthy subjects at baseline and 5, 30, 60, and 90 min after oral administration of theophylline $(0.66 \mathrm{mg} / \mathrm{kg}$, maximum dose of $500 \mathrm{mg}$ ) or placebo in a cross-over design. Baseline results from 17 drug-treated schizophrenic patients were included for comparison. Compared with placebo, theophylline treatment significantly increased $P 50$ ratio (S2/S1) from $0.28 \pm 0.03$ to $0.82 \pm 0.11$ at 30 min and $0.61 \pm 0.07$ at 60 min (mean $\pm S E M)$, which were not significantly different from the schizophrenia group $(0.74 \pm 0.05)$. The increased P50 ratio by theophylline was due to a combined decrease in $S 1$ and increase in S2 amplitude. The impairment of P50 suppression by theophylline in normal subjects suggests a modulatory role of adenosine in sensory gating, which may be related to P50 suppression deficit in schizophrenia and is in agreement with a hypoadenosinergic model of schizophrenia. [Neuropsychopharmacology 27:629-637, 2002] (C) 2002 American College of Neuropsychopharmacology. Published by Elsevier Science Inc.
KEY WORDS: Schizophrenia; Sensory gating; Event related potentials; P50; Theophylline; Adenosine; Purinergic system
The suppression of the P50 component of the auditory event-related potential has been used as an index of sensory gating in neuropsychiatric research (Freedman et al. 1983; Adler et al. 1998 for review). The P50 wave is

dade de Biociências, Pontifícia Universidade Católica do Rio Grande do Sul (PUCRS), Porto Alegre, RS, Brazil (DRL).

Address correspondence to: Diogo R. Lara, M.D., Ph.D., Faculdade de Biociências, PUC-RS, Av. Ipiranga, 6681 - Prédio 12 A, Caixa Postal 1429, Porto Alegre, RS, Brazil 90619-900. Fax: +55 51 3320 3612; E-mail: drlara@pucrs.br

Received July 24, 2001; revised February 12, 2002; accepted March 19, 2002.

Online publication: 3/21/02 at www.acnp.org/citations/Npp 032102273 . 
a small amplitude positive wave occurring about $50 \mathrm{~ms}$ after an auditory stimulus. In the P50 suppression paradigm, when two stimuli are presented $500 \mathrm{~ms}$ apart, the amplitude of the second peak (S2), compared with the first (S1), is usually attenuated in healthy subjects, whereas in patients with schizophrenia or acute mania this suppression is impaired (Adler et al. 1998). The hippocampus has been suggested to mediate P50 suppression and it is generally assumed that impaired suppression in schizophrenia is due to an inhibitory deficit, which leads to an overflow of information and diminished capacity to filter out irrelevant stimuli (Adler et al. 1998). The neurochemical basis of the P50 suppression is not yet completely understood, but cholinergic, GABAergic and monoaminergic systems have been proposed to modulate this phenomenon (Adler et al. 1998; Hershman et al. 1995; Light et al. 1999).

The neuromodulator adenosine exerts potent inhibitory influence on synaptic activity in the CNS (Brundege and Dunwiddie 1997). Four distinct subtypes of adenosine receptors (A1, A2A, A2B and A3) have been cloned and characterized (for review, see Ralevic and Burnstock 1997). A1 receptors are widespread, with high levels in the hippocampus, cerebral cortex, thalamus and cerebellum. By acting on presynaptic A1 receptors, adenosine inhibits the release of several neurotransmitters (including glutamate) and activation of postsynaptic A1 receptors produces neuronal hyperpolarization (Brundege and Dunwiddie 1997). Extracellular adenosine levels markedly increase under excitotoxic conditions and its inhibitory actions provide an important endogenous mechanism of neuroprotection (Brundege and Dunwiddie 1997; Ralevic and Burnstock 1998). Unlike the widespread distribution of A1 receptors, A2A receptors are mostly expressed in dopamine-rich regions, co-localized with D2 receptors (Svenningsson et al. 1999). Activation of A2A receptors reduces the affinity of D2 receptors for agonists, including endogenous dopamine (Ferre et al. 1991; Ferre 1997). Adenosine provides an inhibitory tone in several brain regions, including the hippocampus, and the stimulating effects of the nonselective adenosine A1/A2A antagonists caffeine and theophylline are attributed to the antagonism of this inhibitory tone (Fredholm et al. 1999).

We have recently proposed that a deficit of adenosinergic activity could contribute to the pathophysiology of schizophrenia (Lara and Souza 2000). The interactions of adenosine with the dopaminergic and glutamatergic systems (mainly through A2A and A1 receptors, respectively) would account for the putative alterations of these neurotransmitter systems in schizophrenia and can be supported by the ability of adenosine agonists to reverse the behavioral effects of amphetamine (Ferre 1997; Rimondini et al. 1998) and NMDA antagonists (Browne and Welch 1982; Kafka and Corbett 1996; Popoli et al. 1999; Sills et al. 1999). A deficient neuroprotective role of adenosine in schizophrenia would also render the brain more susceptible to insults and could contribute to the clinical and cerebral deterioration observed in these patients (Mathalon et al. 2001). Evidence of altered adenosinergic activity in schizophrenia includes the upregulation of striatal A2A receptors (Kurumaji and Toru 1998), which could be compensatory to low adenosinergic activity (Lara and Souza 2000) and the clinical improvement of schizophrenic patients with add-on dipyridamole, an inhibitor of adenosine uptake (Akhondzadeh et al. 2000), probably through a non-dopaminergic mechanism (Brunstein et al. 2001). Moreover, clozapine may increase adenosinergic acitivity (Pinna et al. 1999; Lara et al. 2001a), high doses of caffeine exacerbated psychotic symptoms in schizophrenic patients (Lucas et al. 1990) and the A2A receptor is a candidate for a schizophrenia susceptibility gene on 22q12-13 (Deckert et al. 1997).

Of particular interest regarding the P50 suppression paradigm is the work by Mitchell et al. (1993), who showed that when two independent excitatory pathways to CA1 pyramidal neurons are used to evoke field excitatory post-synaptic potential (EPSP), prior activation of one pathway at a physiological level inhibits the EPSP in the other pathway when evoked immediately after. This activity-dependent inhibition lasted $\sim 750 \mathrm{~ms}$, peaking at $250 \mathrm{~ms}$, which is a quite similar time-course compared with the P50 suppression paradigm regarding the interstimuli (S1-S2) intervals (Adler et al. 1998). Importantly, this inhibition was mediated by adenosine, since it was blocked by theophylline and the A1 antagonist CPT, and potentiated by drugs that increase adenosine extracellular availability by inhibiting adenosine uptake and degradation (Mitchell et al. 1993).

Given that P50 suppression consists of an activitydependent inhibition, which resembles the inhibitory role of adenosine in the CNS, the contribution of adenosine to sensory gating was evaluated in healthy subjects submitted to the P50 suppression paradigm before and after oral administration of the adenosine antagonist theophylline or placebo. A group of medicated schizophrenic patients was also included for comparison and for validation of our neurophysiological technique.

\section{MATERIAL AND METHODS}

\section{Subjects}

This study was approved by the Ethical Committee on Human Experimentation of the Hospital de Clínicas de Porto Alegre (HCPA), carried out in accordance with the Declaration of Helsinki and all the participants signed an informed consent form after complete explanation about the potential risks involved in this protocol as well as the purpose of this study in lay terms.

Seventeen healthy volunteers were recruited for this 
study among university students and employees. They were submitted to a semi-structured interview by medical doctors with psychiatric training. Exclusion criteria were DSM-IV in axis I diagnosis (evaluated with MINI), clinical illness and any current use of medicines or drugs of abuse, except for oral contraceptives. All volunteers included in the analysis were non-smokers at the time of the study. Subjects with familiar history of schizophrenia or other psychotic disorders in first or second degree were also excluded, as well as those having a familiar history of any axis I mental disorder in first degree. Seventeen DSM-IV schizophrenic outpatients (nine smokers), previously diagnosed and treated in the hospital outpatient unit were also included for comparison. They were clinically stable for at least six months and were not in use of new generation antipsychotic medications, which can improve P50 suppression (Nagamoto et al. 1996; Light et al. 2000).

\section{Pharmacological Challenge}

Since the present study intended to evidence the effect of adenosine receptor antagonism on sensory gating, we chose a relatively high but within the therapeutic dose of theophylline as used for acute asthma treatment (6.66 $\mathrm{mg} / \mathrm{kg}$ up to a maximum dose of $500 \mathrm{mg}$ ). This dosage is assumed to produce considerable antagonism of both A1 and $\mathrm{A} 2 \mathrm{~A}$ receptors in the CNS, without a significant inhibition of phosphodiesterase activity (Fredholm et al. 1999). Also, volunteers were instructed to abstain from xanthine-containing drinks (coffee, teas, and colas) for at least one week before the first recording, totaling two weeks of wash-out period. Because nicotine can transiently improve P50 suppression in schizophrenic patients (Adler et al. 1998), all patients abstained from nicotine for a minimum of $2 \mathrm{~h}$. Schizophrenic patients also abstained from xanthines for at least $4 \mathrm{~h}$.

The seventeen healthy volunteers were subjected to P50 event-related potential recordings at baseline and four times after oral treatment. Four subjects were excluded from the analysis due to unstable baseline P50 ratio over time (two subjects) or due to overlapping P30 wave (two subjects). Therefore, analysis included 13 healthy non-smoking volunteers $(\mathrm{M} / \mathrm{F}=8 / 5$, mean age $=27 \pm 4$ years). Moreover, baseline $\mathrm{P} 50$ ratios of 17 drug-treated schizophrenic patients $(\mathrm{M} / \mathrm{F}=16 / 1$, mean age $=36 \pm 9$ years, chlorpromazine equivalents $=468 \pm$ $274 \mathrm{mg}$, smoking/non-smoking $=9 / 8$ ) were included for methodology validation and for comparison. Healthy subjects were submitted to two electrophysiologic recording sessions. Under single blinding conditions, they were randomly assigned to theophylline syrup (100 mg per $15 \mathrm{ml}$, mean dose $=446 \pm 64 \mathrm{mg}$ ) mixed with artificial fruit juice or placebo (artificial fruit juice of similar taste, volume and color) in the first session, and one week later, at approximately the same time of the day, to the complementary treatment. P50 evoked potentials were recorded $25 \mathrm{~min}$ before and 5, 30, 60 and $90 \mathrm{~min}$ after treatment administration. These time points were chosen based on pharmacokinetics of theophylline, which reaches maximum serum concentration around 30-40 min after oral administration and has a mean half-life of $9 \mathrm{~h}$ in healthy volunteers (Trepanier et al. 1998).

\section{Electrophysiologic Recordings}

The method for electrophysiologic recordings was based on previously described protocols, with slight modifications (Nagamoto et al. 1996). In brief, subjects were recorded seated, relaxed, and awake with eyes open and fixed on a distant target to decrease drowsiness during the recording. Electroencephalographic activity was recorded from a disk electrode affixed to the vertex $(\mathrm{Cz})$ and referenced to both mastoids. An electroencephalogram (EEG) was made using the 4-channel system Nihon-Kohden MEM-4104K for recording of evoked responses integrated with auditory stimulator. The mean signal was registered in two channels, one for each side of the cranium, and amplified 20,000 times with a bandpass filter between $10 \mathrm{~Hz}$ and $10 \mathrm{kHz}$. EEG was collected during $1 \mathrm{~s}$ for each paired stimulus presented. Trials were rejected if they contained artifacts as indicated by an EEG tension of $\pm 50 \mu \mathrm{V}$ within the second which includes both P50 waves, starting $0.1 \mathrm{~s}$ before the first stimulus. The rejection rate was typically less than $20 \%$ and the recording session lasted 5 to $7 \mathrm{~min}$. Auditory stimuli were presented in a conditioning-testing paradigm with an interpair interval of $500 \mathrm{~ms}$ and interstimuli interval of $10 \mathrm{~s}$. A $0.04 \mathrm{~ms}$ square wave pulse was amplified in the auditory frequencies $(20-12,000 \mathrm{~Hz})$ and delivered through earphones that produce a $2.5 \mathrm{~ms}$ sound with an intensity of $60 \mathrm{~dB}$ sound pressure level above the auditory acuity threshold, which was measured $15 \mathrm{~min}$ before the recordings. Thirty non-rejected waves were added together to give a grand average signal, which was used for analysis. The most positive peak between 40 and $90 \mathrm{~ms}$ after the conditioning stimulus (S1) was selected as the P50 final latency and the wave amplitude was measured relative to the previous negativity, determining the initial latency and the first P50 wave. The test wave (S2) was determined using the corresponding peak between $500 \pm$ $10 \mathrm{~ms}$ away from S1 latency and its amplitude also measured relative to the previous negative peak. Test/conditioning (S2/S1) ratios were calculated by dividing the test P50 amplitude (S2) by the conditioning P50 amplitude (S1). The data were collected by an unblind researcher (E.S.G.) and analyzed by two independent trained raters blinded to treatment and diagnosis (J.B. and A.S.P.). After comparison, the values generated by one of the raters was used and when respective measurements differed more than $5 \mathrm{~ms}$ in latency ( $8 \%$ of the waves), they performed a new collaborative rating. 


\section{Statistical Analysis}

Comparisons of P50 parameters (P50 ratios, S1 and S2 amplitudes and latencies) were performed between the recordings from placebo and theophylline treatments as well as between recordings before and after each treatment in healthy subjects. The P50 ratios by gender were also compared at baseline and after theophylline treatment. The results of healthy subjects were also compared with both baseline recordings of schizophrenic patients and baseline recordings of the non-smokers subgroup of schizophrenia patients. In addition, schizophrenic patients were compared regarding their smoking status.

Comparison parameters were considered apart as dependent variables and the characteristic of the group (theophylline or placebo) as the independent variable. The Wilcoxon test was used for asymmetric paired data from healthy volunteers. Comparisons between schizophrenic patients and healthy subjects were analyzed using a Kruskal-Wallis distribution-free analysis of variance, followed by Mann-Whitney U test if indicated. Statistical significance was considered at $p<.05$ level. All analyses were implemented with the software SPSS 8.0 for Windows.

\section{RESULTS}

In agreement with several previous reports, healthy subjects presented a strong suppression of the P50 response to the second click at baseline $(\mathrm{S} 2 / \mathrm{S} 1=0.28 \pm$ 0.03 - mean \pm S.E.M for all results), with all but one volunteer presenting more than $50 \%$ suppression, whereas 15 of the 17 schizophrenic patients showed less than $40 \%$ suppression $(S 2 / S 1=0.74 \pm 0.05$ ) (Figure 1; Figure 3 for scattergram). Schizophrenic patients, as a group or as subgroups regarding smoking status, showed statistically significant impaired suppression when compared with baseline measurements of healthy controls $(p<.001)$. Also comparing only non-smoking males, healthy controls $(n=8)$ showed better suppression than schizophrenic patients $(\mathrm{n}=8)(p=.002)$.

There was no statistically significant difference between males $(\mathrm{S} 2 / \mathrm{S} 1=0.25 \pm 0.04)$ and females $(\mathrm{S} 2 / \mathrm{S} 1=0.32 \pm$ $0.08)$ in the baseline recordings of healthy subjects and between smokers (S2/S1 $=0.76 \pm 0.08)$ and non-smokers $(\mathrm{S} 2 / \mathrm{S} 1=0.72 \pm 0.08)$ in the schizophrenic patients group.

Compared with placebo, theophylline significantly increased $\mathrm{P} 50$ ratio at $30 \mathrm{~min}(\mathrm{~S} 2 / \mathrm{S} 1=0.82 \pm 0.11)$ and $60 \mathrm{~min}(\mathrm{~S} 2 / \mathrm{S} 1=0.61 \pm 0.07)$ post-treatment, which was not significantly different from the schizophrenia group as a whole and the subgroup of non-smoking schizophrenic patients (Figure 1). Compared with pretreatment, theophylline significantly increased P50 ratio in all post treatment times. There was a small but statistically significant placebo effect over time compared with the pretreatment recording at all time points, except for
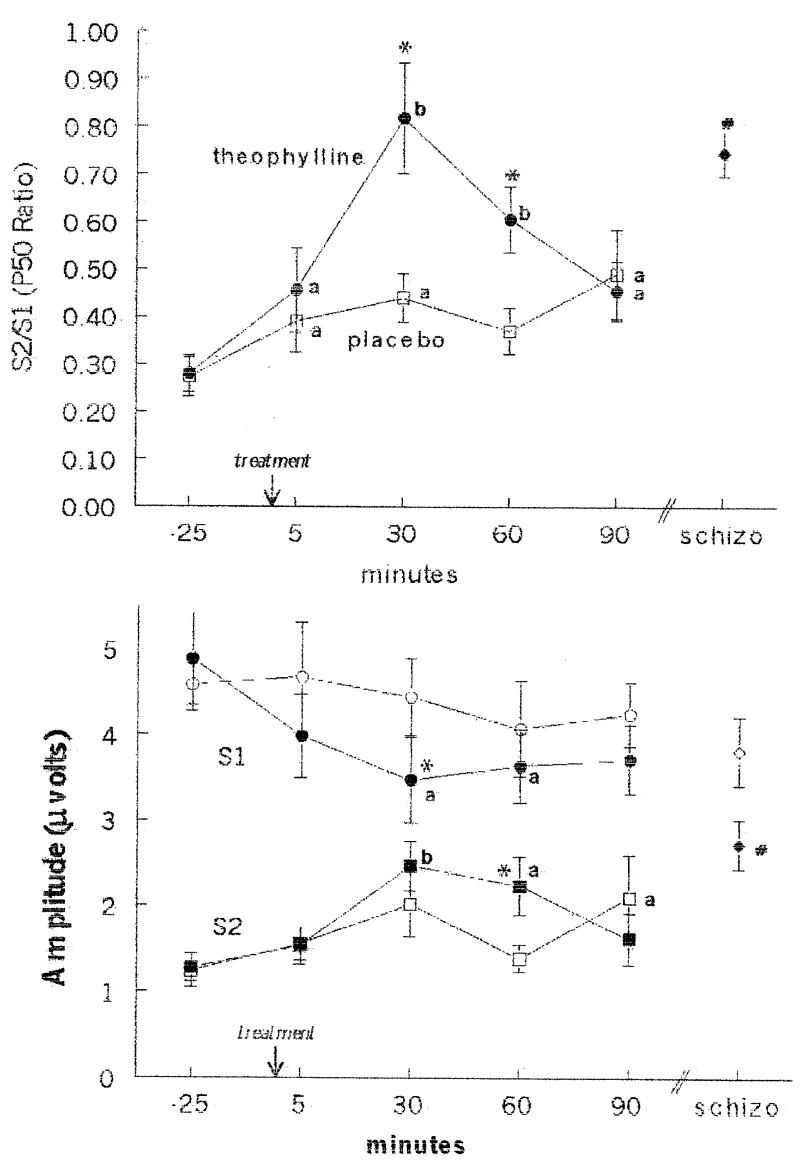

Figure 1. P50 measures of healthy subjects treated with placebo or theophylline and baseline P50 measures of schizophrenic patients. Upper panel: P50 ratios (S2/S1); lower panel: conditioning (S1) and test (S2) amplitudes. Healthy subjects received theophylline ( $)$ or placebo $(\square) 25$ min after a baseline recording. Data from schizophrenic patients $(\bullet)$ are also shown for comparison. Data are mean \pm SEM. $\star=p<.05$ for comparisons within the same time point and $\mathrm{a}=p<.05$ and $\mathrm{b}=p<.01$ compared with pretreatment values (Wilcoxon test). ${ }^{\#}=p<.05$ denotes differences from all points, except for 30 and $60 \mathrm{~min}$ of theophylline group (upper panel) and for 30 and $60 \mathrm{~min}$ from theophylline group and for $90 \mathrm{~min}$ from placebo group for S2 waves (lower panel) (Mann-Whitney U test).

60 min. Representative tracings of a normal subject 30 min after placebo or theophylline as well as a schizophrenic patient are shown in Figure 2. S1 latencies were not statistically different among groups at any time (Table 1).

The effect of theophylline treatment on P50 ratio was similar at all post-treatment times regarding gender subgroups, except at $5 \mathrm{~min}$, when females showed a trend $(p=.06)$ for higher P50 ratios (poorer suppression) than males (Table 2).

The effect of theophylline was due to a decrease in S1 amplitude combined with an increase in S2 amplitude, which peaked at $30 \mathrm{~min}$ (Figure 1; Figure 3 for scatter- 


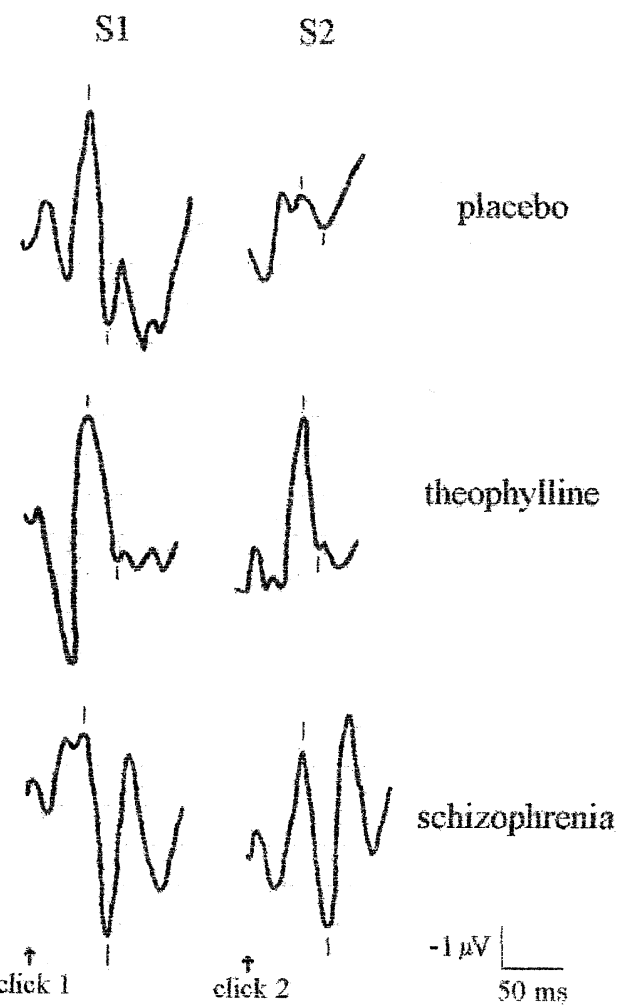

Figure 2. Auditory event-evoked responses to paired stimuli in a healthy subject $30 \mathrm{~min}$ after placebo or theophylline treatment as well as in a schizophrenic patient at baseline. The arrow indicates the click stimulus and the tracings illustrate P50 waves.

gram). Compared with controls at baseline, schizophrenic patients showed a non-significantly lower S1 amplitude and a significantly higher S2 amplitude, which was quite similar to the profile induced by theophylline in healthy subjects at $30 \mathrm{~min}$. In order to allow for more detailed assessment of data, in Figure 3 we show scattergrams of S2/S1 ratio (top panel), S1 wave (middle panel) and S2 wave (bottom panel) of each normal subject and schizophrenic patient. Since the peak effect of theophylline varied between 30 and $60 \mathrm{~min}$ in control subjects and both time points were significantly different from placebo and comparable to schizophrenia (Figure 1), average values of these two time points are presented (designated "mean 30-60") in all scattergrams. As can be seen, the effect of theophylline on P50 ratio, S1, and S2 responses occurs in the majority of subjects, resembling the group profile of schizophrenic patients.

\section{DISCUSSION}

In this study, theophylline increased P50 ratio in healthy subjects from a normal suppression level to a level that could not be distinguished from the P50 suppression deficit of schizophrenic patients. This effect
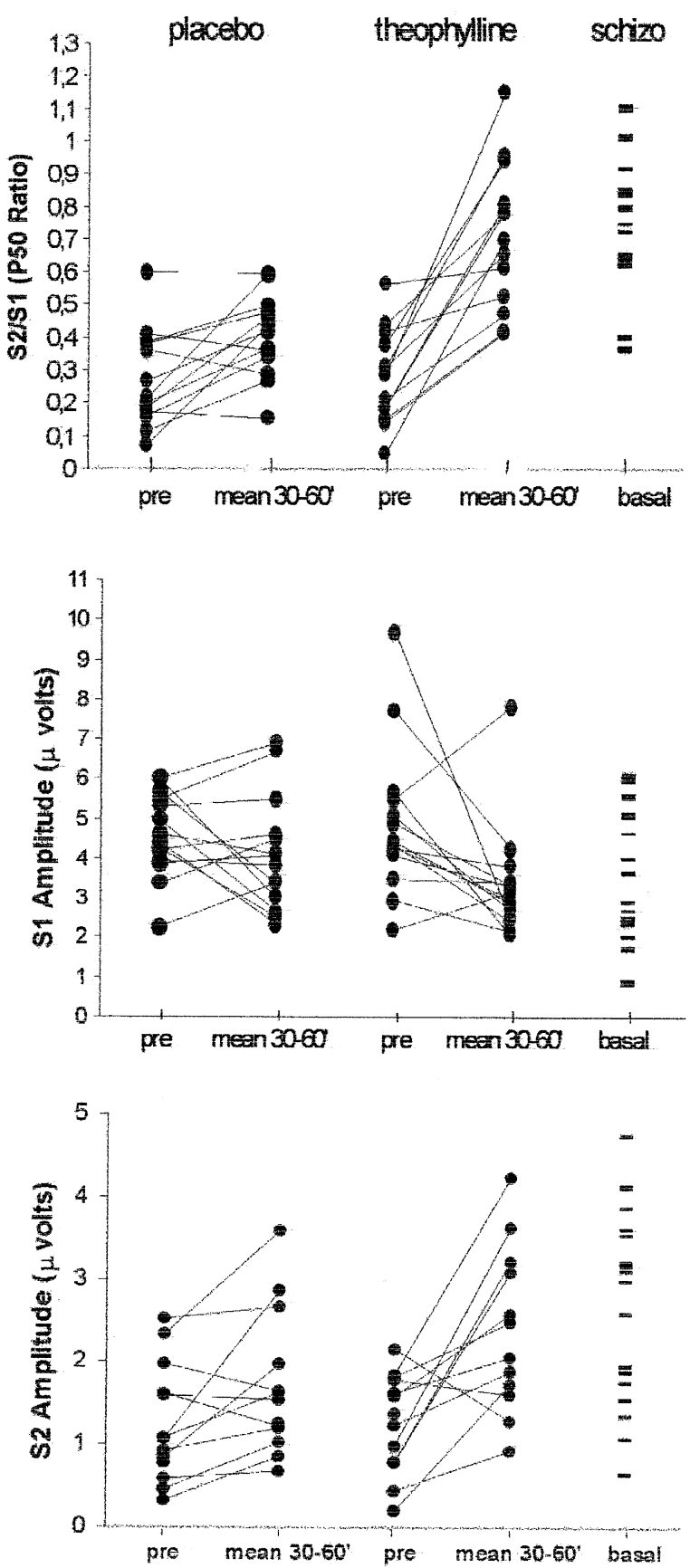

Figure 3. Scattergram of the P50 test/conditioning ratios (S2/S1) (upper panel), S1 (middle panel) and S2 (lower panel) amplitudes in healthy subjects (O) before and after placebo or theophylline treatment, and baseline P50 ratio of schizophrenic patients $(-)$. Pre $=$ pretreatment or baseline measures; mean $30-60^{\prime}=$ mean of $\mathrm{P} 50$ ratios at $30 \mathrm{~min}$ and $60 \mathrm{~min}$ time points for each volunteer; basal = baseline measure from schizophrenic patients.

was obtained both by decreasing S1 amplitude and by increasing S2 amplitude. The deficit in P50 suppression (increased S2 amplitude) has been extensively reported in schizophrenia and is not altered by typical antipsy- 
Table 1. P50 Latency during Treatments.

\begin{tabular}{|c|c|c|c|c|c|}
\hline & Baseline & $5 \mathrm{~min}$ & $30 \mathrm{~min}$ & $60 \mathrm{~min}$ & $90 \mathrm{~min}$ \\
\hline Theophylline & $54.5 \pm 5.5$ & $55.5 \pm 3.4$ & $55.4 \pm 3.4$ & $53.3 \pm 4.3$ & $54.3 \pm 3.0$ \\
\hline Placebo & $54.5 \pm 3.0$ & $55.0 \pm 4.5$ & $55.7 \pm 4.2$ & $55.7 \pm 3.8$ & $55.3 \pm 2.9$ \\
\hline
\end{tabular}

Values are in ms, mean \pm S.D.

chotics (Adler et al. 1998; Light et al. 2000). However, in unmedicated schizophrenic patients reduced S1 amplitude has also been reported (Freedman et al. 1983; Patterson et al. 2000). This may indicate that theophylline-induced alterations in the P50 paradigm more closely resemble the findings in unmedicated schizophrenic patients, but as such subgroup of patients was not included in our study, this hypothesis should be taken cautiously. Nevertheless, our study replicates the well-documented lack of P50 suppression in medicated schizophrenic patients (Figure 1), with fairly normal amplitude of the S1 wave compared with controls, although a relatively small S1 amplitude was observed in some of our patients (see Figure 3, middle panel). Limitations to this study include lack of theophylline blood levels control and toxicology screenings for both volunteers and patients, as well as differences between volunteers and patients, such as age, gender distribution, smoking status and use of antipsychotics, which limit their comparison.

The magnitude of the impairment produced by theophylline on P50 ratio at 30 and $60 \mathrm{~min}$ is in the same order of magnitude of the P50 suppression deficit found in schizophrenia. Interestingly, although not systematically evaluated, six subjects after theophylline treatment spontaneously reported to be disturbed by or became aware of stimuli which were previously considered irrelevant, such as the air conditioning noise, a phenomenon related to reduced sensory gating (Adler et al. 1998).

Sensory gating differences by gender have been discussed in previous works. Using the P50 paradigm, Hetrick et al. (1996) found a trend for diminished suppression in women $(p<.08)$, whereas other studies found no difference (Rasco et al. 2000). In pre-pulse inhibition (PPI), another paradigm to access sensory gating, women showed less inhibition than men (Swerdlow et al. 1993). The present experiment was not specifically designed to compare gender differences, but there was a trend $(p=.06)$ for poorer suppression at 5 min after theophylline treatment in women even in this small sample. The hypothesis that gender affects the P50 response to theophylline treatment should be further investigated.

Since theophylline is a non-selective A1 and A2A receptor blocker, it is unclear which one, or if both receptors have to be blocked in order to produce inhibition of sensory gating. $\mathrm{A} 2 \mathrm{~A}$ receptors are mostly found in dopaminergic regions, where they closely interact with D2 receptors, decreasing their affinity for dopamine (Ferre et al. 1991; Ferre 1997). If adenosinergic deficit is present in schizophrenia, this mechanism could account for increased basal occupancy of D2 receptors by dopamine recently reported in schizophrenia (AbiDargham et al. 2000), but dopaminergic involvement is unlikely to account for the P50 suppression deficits in schizophrenic patients (Adler et al. 1998; Freedman et al. 2000). Moreover, amphetamine, which robustly enhances dopaminergic activity, increased P50 ratio (S2) S1) in humans from 0.24 to 0.48 (Light et al. 1999), which is apparently less pronounced than the alteration induced by theophylline. We therefore hypothesize that blockade of A1 receptors is more likely to account for the diminished P50 suppression induced by theophylline, since: (1) A1 receptors are abundant in the hippocampus, a region probably implicated in P50 suppression and sensory gating (Adler et al. 1998); (2) when activated by adenosine, presynaptic A1 receptors inhibit glutamate release, an event previously suggested to be crucial in the sensory gating mechanism (Adler et al. 1998); (3) in vitro, a selective A1 antagonist mimicked the effect of theophylline in a paired pulse paradigm (Mitchell et al. 1993) and blocked the heterosynaptic inhibition evoked by NMDA administration and tetanic stimulation (Manzoni et al. 1994); and (4) adenosine A1 receptors also potentiated the effect of the dopamine agonist apomorphine in the reduction of prepulse inhibition, another index of sensory gating (Koch and Hauber 1998).

Freedman and colleagues have shown that the P50 suppression deficit in schizophrenic patients are tran-

Table 2. P50 Ratios before and after Theophylline Treatment by Gender.

\begin{tabular}{lccccc}
\hline & Baseline & $\mathbf{5}$ min & $\mathbf{3 0}$ min & $\mathbf{6 0 ~} \mathbf{m i n}$ & $\mathbf{9 0} \mathbf{~ m i n}$ \\
\hline Males & $0.25 \pm 0.04$ & $0.30 \pm 0.05$ & $0.75 \pm 0.13$ & $0.60 \pm 0.07$ & $0.50 \pm 0.07$ \\
Females & $0.32 \pm 0.08$ & $0.71 \pm 0.18$ & $0.94 \pm 0.23$ & $0.62 \pm 0.15$ & $0.38 \pm 0.12$ \\
\hline
\end{tabular}

Values are in percentage, mean \pm SEM. 
siently normalized immediately after a short period of non-REM sleep $(10 \mathrm{~min})$ but not after longer periods (with REM sleep), which can be explained by a resensitization of nicotinic receptors (Adler et al. 1998; Freedman et al. 2000). These data may also be related to the sleep modulating role of adenosine, which reaches higher levels in the initiation of sleep, gradually decreasing to very low levels during REM sleep (Strecker et al. 2000). Indeed, the effect of xanthines (caffeine and theophylline) in delaying sleep onset (Landolt et al. 1995 ) is due to the antagonism of adenosinergic inhibitory activity via A1 receptors in forebrain and mesopontine cholinergic neurons (Strecker et al. 2000). Interestingly, the sleep pattern of schizophrenic subjects, particularly slow-wave sleep deficit at 1-2 Hz (Keshavan et al. 1998), is similar to the pattern induced by caffeine in healthy volunteers (Landlolt et al. 1995), and refractory schizophrenic patients clearly improved sleep after treatment with allopurinol, an inhibitor of purine degradation devoid of sedative effects in non-schizophrenic patients (Lara et al. 2001b).

Cholinergic modulation of the P50 response has been demonstrated with the impairment of sensory gating produced by the $\alpha 7$-nicotinic receptor antagonist $\alpha$-bungarotoxin (Luntz-Leybman et al. 1992) and the linkage between the chromosomal locus of the $\alpha 7$-nicotinic acetylcholine receptor gene and schizophrenia (Freedman et al. 1997; Leonard et al. 1998; Riley et al. 2000), although lack of this association has also been reported (Neves-Pereira et al. 1998; Curtis et al. 1999). Moreover, nicotine administration has also been shown to transiently correct the P50 suppression deficit in schizophrenia (Adler et al. 1998), probably by enhancing excitatory transmission at $\alpha 7$-nicotinic receptors in interneurons (Alkondon et al. 1998), which would then be inhibitory by releasing GABA (or adenosine). It is possible that altered sensory gating in schizophrenic patients is not only related to dysfunctional nicotinic input to interneurons, but may also be at the level of its inhibitory mediator, which is not necessarily GABA. Although a GABA-B antagonist moderately increased S2/S1 ratio from 0.25 to 0.55 in the animal model of the evoked potential paradigm (Hershman et al. 1995), it is noteworthy that activation of $\alpha 7$-nicotinic receptors from human brain interneurons failed to trigger GABAergic postsynaptic currents (Alkondon et al. 2000). Moreover, GABA-A and GABA-B agonists have not been shown to be clinically effective or to improve P50 suppression in schizophrenia despite being available and largely used as psychotropic agents for decades. In contrast, the adenosine reuptake inhibitor dipyridamole, which prolonged activity-dependent inhibition in a paired-pulse paradigm in hippocampal slices (Mitchell et al. 1993), was recently reported as a beneficial adjunctive treatment for schizophrenia (Akhondzadeh et al. 2000), probably through a non-dopaminergic mechanism, since patients were al- ready at haloperidol $20 \mathrm{mg}$ a day (Brunstein et al. 2001). Of note, chronic caffeine intake doubles the consumption of nicotine and facilitates the acquisition of selfadministration behavior in rats (Shoaib et al. 1999), resembling the excessive smoking behavior of schizophrenic patients and supporting the notion of adenosine receptor blockade as a model of schizophrenia. Finally, adenosine A1 receptor blockade by caffeine in rats increases extracellular acetylcholine levels in the hippocampus over fourfold (Carter et al. 1995), which could stimulate low affinity nicotinic receptors such as the $\alpha 7$. This finding suggests that P50 suppression might be disrupted despite increased cholinergic activity, assuming that caffeine also affects P50 ratio as theophylline, which is likely, since their pharmacological profiles are quite similar and theophylline is an active metabolite of caffeine (Fredholm et al. 1999)

In summary, the P50 suppression deficit induced by theophylline in healthy subjects suggest the involvement of the inhibitory neuromodulator adenosine in sensory gating, which is in line with a hypoadenosinergic model of schizophrenia (Lara and Souza 2000). Moreover, adenosine may be the inhibitory mediator of interneurons activated by $\alpha 7$ nicotinic receptors. Finally, intake of xanthines (caffeine and theophylline) prior to the recording session should be considered as a potential bias in the P50 suppression paradigm.

\section{ACKNOWLEDGMENTS}

This research line has been supported by PRONEX (\#41960904-366/96) and FAPERGS.

\section{REFERENCES}

Abi-Dargham A, Rodenhiser J, Printz D, Zea-Ponce Y, Gil R, Kegeles LS, Weiss R, Cooper TB, Mann JJ, Van Heertum RL, Gorman JM, Laruelle M (2000): From the cover: increased baseline occupancy of D2 receptors by dopamine in schizophrenia. Proc Natl Acad Sci USA 97:8104-8109

Adler LE, Olincy A, Waldo M, Harris JG, Griffith J, Stevens K, Flach K, Nagamoto H, Bickford P, Leonard S, Freedman R (1998): Schizophrenia, sensory gating, and nicotinic receptors. Schizophr Bull 24:189-202

Akhondzadeh S, Shasavand E, Jamilian H, Shabestari O, Kamalipour A (2000): Dipyridamole in the treatment of schizophrenia: adenosine-dopamine receptor interactions. J Clin Pharm Ther 25:131-137

Alkondon M, Pereira EF, Albuquerque EX (1998): Alphabungarotoxin- and methyllycaconitine-sensitive nicotinic receptors mediate fast synaptic transmission in interneurons of rat hippocampal slices. Brain Res 810: 257-263

Alkondon M, Pereira EF, Eisenberg HM, Albuquerque EX (2000): Nicotinic receptor activation in human cerebral 
cortical interneurons: a mechanism for inhibition and disinhibition of neuronal networks. J Neurosci 20:66-75

Browne RG, Welch WM (1982): Stereoselective antagonism of phencyclidine's discriminative properties by adenosine receptor agonists. Science 217:1157-1159

Brundege JM, Dunwiddie TV (1997): Role of adenosine as a modulator of synaptic activity in the central nervous system. Adv Pharmacol 39:353-391

Brunstein MG, Belmonte-de-Abreu P, Souza DO, Lara DR (2001): Therapeutic benefit of adjunctive dipyridamole in schizophrenia is probably due to adenosine-glutamate interactions. J Clin Pharm Ther 26:155-156

Carter AJ, O'Connor WT, Carter MJ, Ungerstedt U (1995): Caffeine enhances acetylcholine release in the hippocampus in vivo by a selective interaction with adenosine A1 receptors. J Pharmacol Exp Ther 273:637-642

Curtis L, Blouin JL, Radhakrishna U, Gehrig C, Lasseter VK, Wolyniec P, Nestadt G, Dombroski B, Kazazian HH, Pulver AE, Housman D, Bertrand D, Antonarakis SE (1999): No evidence for linkage between schizophrenia and markers at chromosome 15q13-14. Am J Med Genet 88:109-112

Deckert J, Nothen MM, Bryant SP, Schuffenhauer S, Schofield PR, Spurr NK, Propping P (1997): Mapping of the human adenosine A2a receptor gene: relationship to potential schizophrenia loci on chromosome $22 \mathrm{q}$ and exclusion from the $\mathrm{CATCH} 22$ region. Hum Genet 99:326-328

Ferre S, Euler GV, Johansson B, Fredholm B, Fuxe K (1991): Stimulation of high affinity adenosine A2 receptors decreases the affinity of dopamine D2 receptors in rat striatal membranes. Proc Natl Acad Sci USA 88:7238-7241

Ferre S (1997): Adenosine-dopamine interactions in the ventral striatum: implications for the treatment of schizophrenia. Psychopharmacology (Berl) 133:107-120

Fredholm BB, Bätting K, Holmén J, Nehlig A, Zvartau E (1999): Actions of caffeine in the brain with special reference to factors that contribute to its widespread use. Pharmacol Rev 51:83-153

Freedman R, Adler LE, Waldo MC, Pachtman E, Franks RD (1983): Neurophysiological evidence for a defect in inhibitory pathways in schizophrenia: comparison of medicated and drug-free patients. Biol Psychiatry 18: 537-551

Freedman R, Coon H, Myles-Worsley M, Orr-Urtreger A, Olincy A, Davis A, Polymeropoulos M, Holik J, Hopkins J, Hoff M, Rosenthal J, Waldo MC, Reimherr F, Wender P, Yaw J, Young DA, Breese CR, Adams C, Patterson D, Adler LE, Kruglyak L, Leonard S, Byerley W (1997): Linkage of a neurophysiological deficit in schizophrenia to a chromosome 15 locus. Proc Natl Acad Sci USA 94:587-592

Freedman R, Adams CE, Leonard S (2000): The alpha7-nicotinic acetylcholine receptor and the pathology of hippocampal interneurons in schizophrenia. J Chem Neuroanat 20:299-306

Hershman KM, Freedman R, Bickford PC (1995): GABAB antagonists diminish the inhibitory gating of auditory response in the rat hippocampus. Neurosci Lett 190: 133-136

Hetrick WP, Sandman CA, Bunney WE Jr, Jin Y, Potkin SG,
White MH (1996): Gender differences in gating of the auditory evoked potential in normal subjects. Biol Psychiatry 39:51-58

Kafka SH, Corbett R (1996): Selective adenosine A2A receptor/dopamine D2 receptor interactions in animal models of schizophrenia. Eur J Pharmacol 295:147-154

Keshavan MS, Reynolds CF 3rd, Miewald MJ, Montrose DM, Sweeney JA, Vasko RC Jr, Kupfer DJ (1998): Delta sleep deficits in schizophrenia. Arch Gen Psychiatry 55:443-448

Koch M, Hauber W (1998): Regulation of sensorimotor gating by interactions of dopamine and adenosine in the rat. Behav Pharmacol 9:23-29

Kurumaji A, Toru M (1998): An increase in [3H]CGS21680 binding in the striatum of postmortem brains of chronic schizophrenics. Brain Res 808:320-323

Landolt HP, Dijk D, Gaus SE, Borbély AA (1995): Caffeine reduces low-frequency delta activity in the human sleep EEG. Neuropsychopharmacology 12:229-238

Lara DR, Souza DO (2000): Schizophrenia: a purinergic hypothesis. Med Hypotheses 54:157-166

Lara DR, Vianna M, de Paris F, Quevedo J, Oses JP, Battastini AM, Sarkis JJ, Souza DO (2001a): Chronic treatment with clozapine, but not haloperidol, increases striatal 5 '-nucleotidase activity in rats. Neuropsychobiology 44 : 99-102

Lara DR, Brunstein MG, Ghisolfi E, Lobato MI, Belmontede-Abreu P, Souza DO (2001b): Allopurinol augmentation for poorly responsive schizophrenia. Int Clin Psychopharm 16:235-237

Leonard S, Gault J, Moore T, Hopkins J, Robinson M, Olincy A, Adler LE, Cloninger CR, Kaufmann CA, Tsuang MT, Faraone SV, Malaspina D, Svrakic DM, Freedman R (1998): Further investigation of a chromosome 15 locus in schizophrenia: analysis of affected sibpairs from the NIMH Genetics Initiative. Am J Med Genet 81:308-312

Light GA, Malaspina D, Geyer MA, Luber BM, Coleman EA, Sackeim HA, Braff DL (1999): Amphetamine disrupts P50 suppression in normal subjects. Biol Psychiatry 46: 990-996

Light GA, Geyer MA, Clementz BA, Cadenhead KS, Braff DL (2000): Normal P50 suppression in schizophrenia patients treated with atypical antipsychotic medications. Am J Psychiatry 157:767-771

Lucas PB, Pickar D, Kelsoe J, Rapaport M, Pato C, Hommer D (1990): Effects of the acute administration of caffeine in patients with schizophrenia. Biol Psychiatry 28:35-40

Luntz-Leybman V, Bickford PC, Freedman R (1992): Cholinergic gating of response to auditory stimuli in rat hippocampus. Brain Res 587:130-136

Manzoni OJ, Manabe T, Nicoll RA (1994): Release of adenosine by activation of NMDA receptors in the hippocampus. Science 265:2098-2101.

Mathalon DH, Sullivan EV, Lim KO, Pfefferbaum A (2001): Progressive brain volume changes and the clinical course of schizophrenia in men: a longitudinal magnetic resonance imaging study. Arch Gen Psychiatry 58:148-157

Mitchell JB, Lupica CR, Dunwiddie TV (1993): Activitydependent release of endogenous adenosine modulates synaptic responses in the rat hippocampus. J Neurosci 13:3439-3447 
Nagamoto HT, Adler LE, Hea RA, Griffith JM, McRae KA, Freedman R (1996): Gating of auditory P50 in schizophrenics: unique effects of clozapine. Biol Psychiatry 40:181-188

Neves-Pereira M, Bassett AS, Honer WG, Lang D, King NA, Kennedy JL (1998): No evidence for linkage of the CHRNA7 gene region in Canadian schizophrenia families. Am J Med Genet 81:361-363

Patterson JV, Jin Y, Gierczak M, Hetrick WP, Potkin S, Bunney WE, Sandman CA (2000): Effects of temporal variability on P50 and the gating ratio in schizophrenia: a frequency domain adaptive filter single-trial analysis. Arch Gen Psychiatry 57:57-64

Pinna A, Wardas J, Cozzolino A, Morelli M (1999): Involvement of adenosine $\mathrm{A} 2 \mathrm{~A}$ receptors in the induction of c-fos expression by clozapine and haloperidol. Neuropsychopharmacology 20:44-51

Popoli P, Reggio R, Pèzzola A (1997): Adenosine A1 and A2 receptor agonists significantly prevent the eletroencephalographic effects induced by MK-801 in rats. Eur J Pharmacol 333:143-146

Ralevic V, Burnstock G (1997): Receptors for purines and pyrimidines. Pharmacol Rev 50:413-492

Rasco L, Skinner RD, Garcia-Rill E (2000): Effect of age on sensory gating of the sleep state-dependent P1/P50 midlatency auditory evoked potential. Sleep Res Online 3:97-105

Riley BP, Makoff A, Mogudi-Carter M, Jenkins T, Williamson R, Collier D, Murray R (2000): Haplotype transmission disequilibrium and evidence for linkage of the
CHRNA7 gene region to schizophrenia in Southern African Bantu families. Am J Med Genet 96:196-201

Rimondini R, Ferré S, Giménez-Llort L, Ögren SO, Fuxe K (1998): Differential effects of selective adenosine A1 and A2a receptor agonists on dopamine receptor agonist induced behavioral responses in rats. Eur J Pharmacol 347:153-158

Shoaib M, Swanner LS, Yasar S, Goldberg SR (1999): Chronic caffeine exposure potentiates nicotine self-administration in rats. Psychopharmacology (Berl) 142:327-333

Sills TL, Azampanah A, Fletcher PJ (1999): The adenosine A1 receptor agonist N6-cyclopentyladenosine blocks the disruptive effect of phencyclidine on prepulse inhibition of the acoustic startle response in the rat. Eur J Pharmacol 369:325-329

Strecker RE, Morairty S, Thakkar MM, Porkka-Heiskanen T, Basheer R, Dauphin LJ, Rainnie DG, Portas CM, Greene RW, McCarley RW (2000): Adenosinergic modulation of basal forebrain and preoptic/anterior hypothalamic neuronal activity in the control of behavioral state. Behav Brain Res 115:183-204

Svenningsson P, Le Moine C, Fisone G, Fredholm BB (1999): Distribution, biochemistry and function of striatal adenosine A2A receptors. Prog Neurobiol 59:355-396

Swerdlow NR, Auerbach P, Monroe SM, Hartston H, Geyer MA, Braff DL (1993): Men are more inhibited than women by weak prepulses. Biol Psychiatry 34:253-260

Trepanier EF, Nafziger AN, Amsden GW (1998): Effect of terbinafine on theophylline pharmacokinetics in healthy volunteers. Antimicrob Agents Chemother 42:695-697 